\title{
Unemployment as a Risk Factor for Mental Illness: Combining Social and Psychiatric Literature
}

\author{
Shuo Zhang ${ }^{1}$, Vishal Bhavsar ${ }^{2}$ \\ ${ }^{1}$ King's College Medical School, King's College London, London, UK \\ ${ }^{2}$ Institue of Psychiatry, King's College London, London, UK \\ Email: shuo.s.zhang@kcl.ac.uk, vishal.2.bhavsar@kcl.ac.uk
}

Received February $15^{\text {th }}, 2013$; revised March $16^{\text {th }}, 2013$; accepted March $23^{\text {rd }}, 2013$

Copyright (C) 2013 Shuo Zhang, Vishal Bhavsar. This is an open access article distributed under the Creative Commons Attribution License, which permits unrestricted use, distribution, and reproduction in any medium, provided the original work is properly cited.

\begin{abstract}
Unemployment has been shown to have wide ranging effects on physical and mental health. This review looks to clarify the relationship between unemployment and mental illness specifically, in terms of establishing causality, effect size and moderating factors. The current rational for research combines an etiological approach and interest in the social causation of disease with past work from a social psychological perspective. For this review, PsychInfo, Medline and Embase databases were searched between the years of 1970 and 2011, for prospective studies that include unemployment and mental illness terms. 10 studies were found which matched the inclusion criteria. Studies were included if they studied the long term unemployed, defined the age and gender of their study population, defined their outcome measurements in medical terms, and followed a population prospectively over time. Overall unemployment did precede mental illness; however the exact effect size is unclear. A quantitative meta-analysis was not conducted due to the variability in study design. The discussion tries to point to methodological and theoretical limitations that affect investigations into unemployment and mental illness. It concludes that the work has so far been skewed by individual biases, and that there needs to be wider collaboration between the social sciences and psychiatry.
\end{abstract}

Keywords: Unemployment; Mental Illness; Schizophrenia; Depression; Etiology

\section{Introduction}

Unemployment defines a section of the population who is not currently at work but has the capacity to, and is actively seeking to work (Collins English Dictionary, 2011). Unemployment has been shown to negatively impact both physical and mental health (Brenner, 1988). The first descriptive studies characterized mental health related outcomes as "depression, anxiety, poor self-esteem, isolation and strain on the family" (Donovan et al., 1987). Further many cross-sectional studies have demonstrated an association between unemployment and mental illness (Paul \& Moser, 2009). Perhaps it is because the impacts of unemployment are so common sense and wide ranging that the topic has attracted limited interest from psychiatry. There has been much work on the mental health impacts of unemployment but very little on its relationship with clinically defined mental illness. Work on unemployment and mental illness has so far looked mainly at rates of employment in people who already have a psychiatric diagnosis (Marwaha et al., 2007), and re-employment as a positive goal in the recovery from disease episodes (Secker et al., 2001). Although work in looking at general impacts of unemployment and mental health has been fruitful, little has focused specifically on unemployment as a prospective risk factor for mental illness.

Unemployment has been investigated in the broader context of physical illness. Interest in the health consequences of unemployment began in earnest in the 1980s with the last eco- nomic depression. Unemployment has been found to be associated with overall morbidity and mortality as well as poorer scores on a range of health outcome measurements (Graetz, 1993). Brenner (1979) previously inferred consequent cardiovascular impacts from the somatization of the stress response; however investigations have not confirmed any significant results (Kasl \& Cobb, 1980). What is interesting is that health seems to be mediated by factors like social support. Gore (1978) found that the unemployed who also lacked social support had the highest rise in blood cholesterol. Linn et al. (1983) found that the unemployed visited the doctor more, took more medication, and spent more sick days in bed, even though they did not have more diagnosis of physical illness than the employed. This suggests that there is a significant psychological component to physical illness in unemployment.

This paper reviews the studies conducted so far which look at the effect of unemployment on mental illness prospectively and assesses the potential of this approach in furthering the understanding of social factors in the etiology of mental illness. It aims to summarize the findings of the studies, and critically assess the underlying methodological and theoretical assumptions with the view of making recommendations for future research. Research into unemployment and mental illness poses many challenges in terms of the consistency of databases, outcome measurements, and control of contextual factors. It also raises important questions in terms of effect size, moderating factors and direction of causality. These questions and chal- 
lenges are common for other social etiological factors in mental illness. It is hoped that a better understanding of unemployment as a risk factor will inform the wider field.

\section{Unemployment as a Prospective Risk Factor}

The motivations for looking at unemployment specifically as a social risk factor in the development of psychiatric illness come from a few different rationales. Previously the bulk of the work has been by social psychologists with a view of advocating socioeconomic policies that are cognizant of public mental health consequences, and the subsequent healthcare and productivity costs. The current shift in focus to investigating unemployment as a risk factor comes from a synthesis of recent developments within psychiatric epidemiology and the social causation of mental illness with past work in social psychology.

Firstly there has been renewed interest in the social causation of disease, and in the factors that increase the incidence of mental illness (Ferrie, 2001; Marmot, 1978). Furthermore the health impacts of unemployment offers a mechanism that links social, psychological and biological impacts. Bartley (1994) proposes four types of explanations for the impacts of unemployment: poverty, stress, health related behavior and the effect of unemployment on the rest of the work career. These mechanisms have mixed impacts on physical and mental health; the reactions to financial strain and change in status can have physical health impacts directly or lead to the somatization of stress response, and to poorer health behaviors such as substance abuse and less physical activity

At the same time, there has been a revival of interest into social factors in the etiology of diseases such as schizophrenia (Tandon, 2008). Recent work on urbanicity and migration using an epidemiological approach has been fruitful in understanding the role of social stress in mental illness (Cantor-Graae \& Selten, 2005). The current interest in unemployment and mental illness comes in part from past interest in the role of social factors such as migration and urbanicity in the etiology of schizophrenia. Many similarities can be drawn from looking at the theoretical and methodological approaches of past investigation. It also exposes the challenges of disentangling a web of common moderating factors and proposed mechanisms for migration, urbanicity and unemployment (Tandon, 2008). The environmental factors which predisposes us to developing mental illness is still not well understood. However epidemiological risk factors are already used for clinical practice, for example the presence of physical disease, social stresses, interpersonal difficulties and lack of social support in the development of depression (Semple \& Smyth, 2009). Therefore any approach which clarifies these interactions will also increase our understanding of the social causation of mental illness.

\section{Previous Approaches from Social Psychology}

There has been a century of work on the mental health impacts of unemployment within a social psychology framework. Important meta-analytic reviews which summarise the field include (Paul \& Moser, 2009, Murphy \& Athanasou, 1999, McKee-Ryan et al., 2005). In common they possessed a prospective approach to clarify direction of causal effect, the effect size and the interaction of unemployment with other variables such as gender, employment duration and financial hardship. Studies on unemployment and mental illness have so far all been from a social psychological perspective, therefore it is important to be aware of the theoretical and methodological contexts of the field.

The theoretical basis of research has so far been framed in terms of the work on unemployment and mental health by three theorists. Jahoda's (1982) deprivation theory first proposed a mechanism by which unemployment caused mental distress through negative affect on a range of 5 factors: time structure, social contact, collective purpose, status and activity. Warr (1987) developed this idea to include further environmental factors termed "vitamins" that had more complex relationships with the effects of unemployment. These "vitamins" varied with subjective measures of wellbeing that vary with exposure in a more complicated way. In contrast to the two, Fryer (1986) emphasized the importance of human agency as a mediator of the effect of unemployment on mental health, and also re-establishes a role for material deprivation as a significant contributing factor. All three theorists therefore conceptualize the impact of unemployment as an effect of qualities of the external environment upon an individual.

Methodologically this has led to an investigative approach that looked to clarify the association and describe the nature and extent of the impacts. Therefore past reviews have focused on questions of effect size, moderator variables such as gender, age and duration of unemployment, and the problem of causality. This review acknowledges the relevance of these concerns on the more specific question at hand in clarifying causal mechanisms. It aims to depart from previous reviews by assessing the benefits and challenges of an epidemiological approach investigating unemployment as a risk factor in developing mental illness as opposed to clarifying its impacts on mental health.

\section{Methods}

A comprehensive literature search was undertaken. The databases MEDLINE, psychINFO and EMBASE were used for relevant publications from January 1970 to November 2011. Key words "unemployment" and/or "employment" were used to describe job status and "psychosis", "schizophrenia”, "depression" and/or "mental health" for the range of health consequences. "Cohort" was added to limit our search to prospective studies. These were combined for our total number of hits. Table 1 illustrates the results retrieved according to keyword categories and databases.

An initial literature search resulted in a total of 116 results. Inclusion and exclusion criteria focused the results to the question at hand: 1) subjects had to be long term unemployed, how this is defined was database dependent but a minimum criterion of longer than 12 weeks was thought reasonable; 2) Study had to

Table 1.

Number of results according to keyword categories and databases.

\begin{tabular}{ccccc}
\hline \multirow{2}{*}{ Keyword } & \multicolumn{4}{c}{ Database } \\
\cline { 2 - 5 } & Psych Info & Medline & Embase & Total \\
\hline Job status & 14,371 & 37,474 & 54,303 & 106,148 \\
$\begin{array}{c}\text { Mental } \\
\text { disorders }\end{array}$ & 253,416 & 18,5063 & 396,725 & 835,204 \\
Cohort & 58,809 & 129,566 & 104,174 & 292,549 \\
And & 41 & 65 & 10 & 116 \\
\hline
\end{tabular}


be prospective, therefore involving some sort of follow up over time; 3) Outcome measures had to be clinically based, i.e. when medical help was sought, or DSM and other diagnostic scoring systems; 4) The population had to be defined in terms of gender, and/or age and sociodemographic measures. Figure 1 illustrates the search tree. 3 results came from our initial search, further results came from cross referencing and hand searches.

\section{Results}

10 studies are included in our results. These results are summarised in Table 2. Overall there were 4 studies from Scandinavian countries (Lamberg et al., 2010; Agerbo et al., 2010; Hämäläinen et al., 2005; Agerbo et al., 1998), 2 from Britain (Weiss \& Lewis, 1998; Bolton \& Oatley, 1987), 2 American studies (Dew \& Bromet, 1992; Dooley \& Catalano, 1994), 1 German (Frese \& Mohr, 1987) and 1 study from New Zealand (Fergusson \& Horwood, 1997). The studies used a mix of clinical and self-report diagnostic criteria: 6 studies examined depression (Lamberg et al., 2010; Hämäläinen et al., 2008; Frese \& Mohr, 1987; Bolton \& Oatley, 1987; Dew \& Bromet, 1992; Dooley \& Catalano, 1994) whereas four looked at common mental disorders that included depression and anxiety (Fergusson \& Horwood, 1997; Weiss and Lewis, 1998; Agerbo et al., 2010; Agerbo et al., 1998) There were none that focused on schizophrenia specifically. There was a trend in study design with the earlier studies from the late 1980s user smaller cohort groups that were individually followed up to later large scale population based studies from the 1990s.

\section{Discussion}

\section{Unemployment as a Risk Factor, What Are the Findings?}

\section{Effect Size}

All the results show quantitatively that unemployment in-

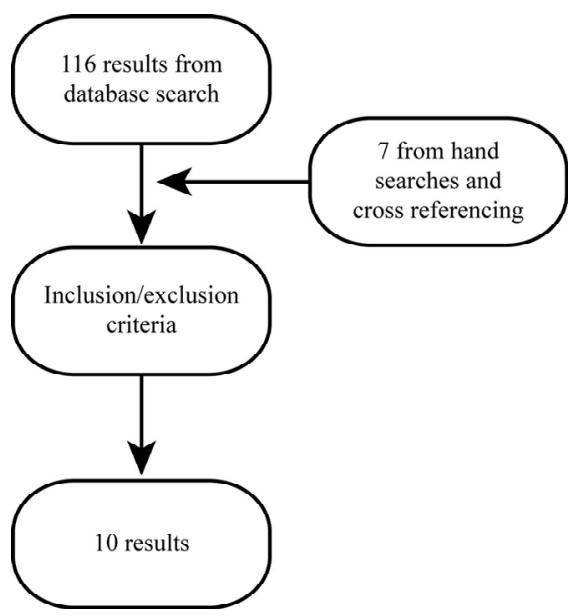

Figure 1.

Search tree.

Table 2.

Summary of Studies.

\begin{tabular}{|c|c|c|c|c|c|c|c|c|}
\hline Author & Year & Country & Data Source & $\begin{array}{l}\text { Sample } \\
\text { Size }\end{array}$ & Age & Mental Illness Studied & Diagnostic Criteria & $\begin{array}{l}\text { Other Factors } \\
\text { Investigated }\end{array}$ \\
\hline Frese M., Mohr G., & 1987 & Germany & $\begin{array}{l}\text { Administered } \\
\text { questionnaires }\end{array}$ & 51 & $\begin{array}{l}\text { over } 45 \text {, } \\
\text { men }\end{array}$ & depression & $\begin{array}{l}\text { Zung's depression } \\
\text { scale }\end{array}$ & $\begin{array}{l}\text { hope for control, } \\
\text { financial problems }\end{array}$ \\
\hline Bolton W., Oatley K. & 1987 & Britain & $\begin{array}{l}\text { interviews at job } \\
\text { centres }\end{array}$ & 49 & $\begin{array}{l}20 \text { - 59, } \\
\text { men }\end{array}$ & depression & $\begin{array}{l}\text { Beck’s depression } \\
\text { inventory }\end{array}$ & $\begin{array}{l}\text { social support, } \\
\text { emotional support, } \\
\text { material assistance, }\end{array}$ \\
\hline $\begin{array}{l}\text { Dew A. M., Bromet E. J. } \\
\text { Penkower L. }\end{array}$ & 1992 & USA & $\begin{array}{l}\text { panel data from a } \\
\text { factory lay off }\end{array}$ & 141 & women & depression and anxiety & $\begin{array}{l}\text { Hopkins Symptom } \\
\text { Checklist }\end{array}$ & effects of gender \\
\hline Dooley D., Catalano R. & 1994 & USA & $\begin{array}{c}\text { Epidemiologic } \\
\text { Catchment Area Study }\end{array}$ & 8278 & adult & depression & DSM-III & reverse causality \\
\hline $\begin{array}{l}\text { Fergusson D.M., Horwood } \\
\text { L. J., Lynskey M. T. }\end{array}$ & 1997 & $\begin{array}{c}\text { New } \\
\text { Zealand }\end{array}$ & $\begin{array}{l}\text { Christchurch Health } \\
\text { and Development } \\
\text { Study }\end{array}$ & 1265 & up to 18 & $\begin{array}{c}\text { major depression, anxiety } \\
\text { disorders, conduct disorder, } \\
\text { other substance } \\
\text { abuse/dependence and } \\
\text { attempted suicide }\end{array}$ & DSM- IV & $\begin{array}{l}\text { time of exposure, also } \\
\text { social, family and } \\
\text { personal factors }\end{array}$ \\
\hline $\begin{array}{c}\text { Agerbo E. Eriksson T. } \\
\text { Mortensen P. } \\
\text { Westergard-Nielsen, }\end{array}$ & 1998 & Denmark & $\begin{array}{l}\text { merging Central } \\
\text { Psychiatric Case } \\
\text { register and data from } \\
\text { Danish administrative } \\
\text { registers }\end{array}$ & $<15,000$ & $16-75$ & common mental disorders & admissions & $\begin{array}{l}\text { income, gender, impact } \\
\text { of business } \\
\text { cycles/stigmatisation } \\
\text { hypotheses }\end{array}$ \\
\hline $\begin{array}{c}\text { Hämäläinen J., Poikolainen } \\
\text { K., Isometsä E., Kaprio J., } \\
\text { Heikkinen M., Lindeman } \\
\text { S., Aro H. }\end{array}$ & 2005 & Finland & $\begin{array}{l}1996 \text { Finnish Health } \\
\text { Care Survey }\end{array}$ & 5993 & & major depression & $\begin{array}{l}\text { institutionalization } \\
\text { and UM-CIDI } \\
\text { Short Form }\end{array}$ & $\begin{array}{l}\text { frequent alcohol } \\
\text { intoxication }\end{array}$ \\
\hline $\begin{array}{c}\text { Agerbo E., Eriksson T., } \\
\text { Mortensen P., } \\
\text { Westergard-Nielsen, }\end{array}$ & 2010 & Denmark r & $\begin{array}{l}\text { merging Central } \\
\text { Psychiatric Case } \\
\text { register with data from } \\
\text { Danish administrator } \\
\text { registers }\end{array}$ & $<15,000$ & $16-65$ & common mental disorders & admissions & $\begin{array}{l}\text { previous unemployment, } \\
\text { duration, business cycle }\end{array}$ \\
\hline $\begin{array}{c}\text { Lamberg T., Virtanen P., } \\
\text { Vahtera J., Luukkaala T., } \\
\text { Koskenvu. }\end{array}$ & 2010 & Finland & $\begin{array}{c}\text { Finnish HeSSup } \\
\text { population sample }\end{array}$ & 14,487 & & depression & $\begin{array}{l}\text { Beck’s depression } \\
\text { inventory }\end{array}$ & retirement \\
\hline
\end{tabular}


creased the measures of mental disorders. The prospective design of the studies shows that unemployment precedes the development of mental illness, therefore suggests a causal mechanism. A meta-analysis was not undertaken because of the large variation in study design and outcome measures. Only 3 papers gave their results in terms of an odds ratio (Dooley \& Catalano, 1994; Weiss \& Lewis, 1998; Hämäläinen et al., 2005) which was insufficient for further statistical analysis. The odds ratios all fell within a comparable range, from ODs 1.78, 95\% CI 1.38 - 2.29 (Hämäläinen et al., 2005 ) to 2.08, 95\% CI 1.38 - 2.77 (Dooley \& Catalano, 1994). From a theoretical perspective clarifying the effect size is important in terms of assessing the effect size of a particular risk factor, and its causal relatedness. However, here it may be more useful to look at interactions with confounding factors and the underlying motivations of the authors in study design. The review goes on to discuss these biases which form the context of methodological and theoretical limitations which effect the interpretation of unemployment as a risk factor.

\section{Reverse Causality}

This has been a key concern of past studies (Paul \& Moser, 2009). Symptoms of mental illness, such as social withdrawal and behavioral disorders have been thought to lead to job loss. Also mental illness might impede a person's capacity to find a job. In this review only Dooley and Catanalo (1994) explicitly addressed the question that depression predisposes to unemployment through quantitative analysis. They found no significant association between depression and unemployment. However the authors were unconvinced, as they found that other health diagnoses predict unemployment. They proposed that discrimination labor laws prompted employers to give other reasons for firing workers instead of their depression. This therefore raises the problem of bias in the data captured.

\section{Methodological limitations}

\section{Study Selection}

Challenges in study selection comes mainly from the large number of studies from social psychology and occupational psychology which look at the effect of unemployment on mental health using very general measures. Diversity in study design presented many results which satisfied the inclusion criteria but also had other directions of interest. It was decided to include this breadth. A limitation of the search is that some studies could not be captured due to being in social science databases, however it is hoped that with the addition of hand searches and cross referencing the search was in the end comprehensive.

\section{Outcome Measurements}

The impacts of unemployment have been investigated in terms of health and mental health outcomes, with mental illness being a specific measure of wider mental health outcomes. The papers used different outcome measurements due to the scope and interests of their own studies. Dew and Bromet (1992) looked at increases in symptomology. Others (Fergusson \& Horwood, 1997) divided data along the extent and duration of unemployment, therefore illustrating the diversity of experiences the category could encompass, thus complicating both data collection and interpretation. Paul and Moser (2009) addressed this problem by segregating their results and looking at the impact of moderator variables on effect size. In terms of unemployment and mental health, motivations for research have been so far focused on articulating the extent of these mixed symptoms of distress as well as in putting forward tentative explanatory mechanisms. Clarifying the impacts of unemployment on mental illness is limited by how mental illness is measured. Mental illness is both a discrete diagnosis and varies in severity, which means that it is often taken to be an increase in symptomology and be more subjective. Further having symptoms of mental illness may not lead to a clinical diagnosis. This is particularly true in generalized conditions such as depression and anxiety. Therefore the studies have tended to ignore more strict clinical criteria, and instead focused on proving negative affect. Agerbo et al. $(1998,2010)$ did use more direct cut offs, like admissions to hospital and seeking medical service, but two separate data sets had to be combined, one of admissions and one of employment data. Other studies used selfreport scales, which although clinical captured a range of ratings. A way of reducing this variance would be to look at a mental illness such as schizophrenia which has a smaller spectrum of symptoms. A key question that needs to be addressed first is whether measuring an increase in symptoms would be useful for unemployment research.

\section{Database}

The collection of data poses many challenges as unemployment is a much more variable social factor, therefore it is more difficult to capture and track. Prospective data sets for these studies were captured on a population level with a long term follow up (Lamberg et al., 2010; Weiss \& Lewis, 1998), or through recurrent interviews with a selected number of smaller samples (Frese \& Mohr, 1987; Bolton \& Oatley, 1987; Dew \& Bromet, 1992). The methods selected perhaps depended on the quality of data already available, for example the Scandinavian studies (Lamberg et al., 2010; Agerbo et al., 2010; Hämäläinen, 2005; Agerbo et al., 1998) were able to make use of comprehensive social data set gathered centrally. However even this is challenging, Agerbo et al. $(1998,2010)$ for example had to combine data sources. The differences in data capture also make it difficult to compare the effect of the duration of unemployment.

\section{Contextual Factors}

There are country specific factors which influence the interpretation and comparison of studies from across different societies and also time frames. Factors include year of data collection, the economic development of the country, and the level of individualism/collectivism (Paul \& Moser, 2009). These offer both practical and conceptual challenges. These differences in data, such as varying business cycles can provide evidence for the economic stress hypothesis (Dooley \& Catalano, 1983) which proposes that negative impacts of unemployment are less during an economic downturn when being unemployed is no longer so stigmatizing. Therefore country specific factors such as the level of social support, and general economic performance also effect the interpretation of theory.

\section{Methodological Limitations}

\section{Moderator Variables}

The effect of unemployment is mediated by many other variables. These create challenges to understanding the causal 
relationship between unemployment and mental illness. Each study has its own theoretical basis from which different mechanisms are clarified, as reflected by the diversity of study design.

Gender has been suggested to mediate the effect of unemployment on mental illness through differences in perceived identity, interpersonal relationships, and social stigmatization (Paul \& Moser, 2009). Papers (Frese \& Mohr, 1987; Bolton \& Oatley, 1987) published in the late 1980s used single sex cohorts; this perhaps reflected the lesser degree of gender equality in the work force at that time. Dew and Bromet (1992) found that that unemployment has a lesser impact on women and proposed that this was due to different gender roles with women valuing their jobs less and gaining more self-esteem from their family. Interestingly one of the single sex male studies looked at the role of social support as mediating mental illness (Bolton \& Oatley, 1987). It is well established that gender interacts with other variables, however it has yet to be determined conclusively whether there is a gender bias in the mediating effects of social or partner support; so far there has been no studies that have looked at its impacts in both sexes. Social support is also a moderating factor in its own right (Paul \& Moser, 2009). Hämäläinen et al. (2005) looked at unemployment and alcohol intoxication, which is in itself a risk factor for depression. It also suggests a role for gender specific behaviours in the reaction to unemployment.

Age was another factor of interest to some of the studies. Fergusson and Horwood (1997) looked at young people, whereas Lamberg et al. (2010) looked at those close to retirement age. These two cohorts would have very different expectations of employment. The papers also have different interests, Fergusson and Horwood (1997) focusing on predisposing factors, and Lamberg et al. (2010) on the links with disability retirement and its subsequent economic impact. Frese and Mohr (1987) looked at the impact of financial deprivation, and tried to assert the impact of financial stress, leading to learned helplessness and a stigmatizing status. These research directions come from the theoretical context of social psychology in clarifying causal mechanisms and relationships of unemployment and mental illness. Moderating factors such as gender, social support, age and financial deprivation are also important etiological factors in depression and schizophrenia. Importantly this illustrates the wealth of information that studies on unemployment and mental illness can contribute to clarifying causal mechanisms of other risk factors. The recent AESOP paper (Reininghaus et al., 2008) did try to synthesis results within a theoretical framework. Proposed mechanisms for the effect of migration involve increased social stress, expectation- reality mismatch and change in social status and self-perception. Further, both the effects of migration and urbanicity seem to be moderated by other factors such as gender, age, and ethnicity. This highlights the importance of understanding environmental and experiential predisposing factors such as unemployment in the broader etiological framework.

\section{Quality of Employment?}

Key theoretical assumptions that underpin research into unemployment and mental illness depend on unemployment conceptualized as a loss of certain qualities. Unemployment as a variable presumes that employment provides the individual with certain benefits, such as time structure, money, and status, the lack of which will cause mental illness. However there has been a recent shift in the field of social psychology into looking at the qualities of employment, and how that impacts on mental health. It has been argued that it is not employment per se that is protective against mental distress, but the quality of that employment and the perceived security of that job (Burchell et al., 2002).

\section{Future Recommendations}

Unemployment is a difficult risk factor to study due to methodological and theoretical challenges. However, a combined approach across the social and epidemiological sciences to incorporate employment histories in prospective population databases may offer a solution. Already databases such as AESOP are beginning to incorporate such information, although so far its analysis has used cross-sectional data and therefore could not ascertain any causal relationships directly. There should be greater collaboration between different studies to include a breadth of measures that characterize a person's employment status. Further it might be conducive to set up collaborations with social science. Important questions which still need to be answered are: 1) should unemployment be incorporated as a confounder in other etiological studies that look at for example migration, or urbanicity; 2) to what extent do these factors interact with each other; and 3) to what extent can we clarify these interactions through investigation.

\section{Conclusion}

Unemployment does increase the risk for going on to develop mental illness. The evidence is strong for depression and anxiety, although the exact effect size is unclear. No studies were found that look at the unemployment and schizophrenia. This review points to both the methodological and theoretical challenges in trying to clarify such etiological relationship. However it also emphasizes the benefits of collaboration between psychiatry and the social sciences. Understanding the role of unemployment as a risk factor is beneficial for future clinical and socioeconomic interventions. The focus should be on developing a consistent methodological approach that clarifies the theory.

\section{REFERENCES}

Agerbo, E., Eriksson, T., Mortensen, P., \& Westergard-Nielsen, N. (2010). Unemployment and mental disorders: Evidence from Danish panel data. International Journal of Mental Health, 39, 56-73. doi:10.2753/IMH0020-7411390203

Agerbo, E., Eriksson, T., Mortensen, P., \& Westergard-Nielsen, N. (1998). Unemployment and mental disorders-An empirical analysis. working paper, Centre for Labour Market and Social Research.

Bartley, M. (1994). Unemployment and ill health: Understanding the relationship. Journal of Epidemiology and Community Health, 48, 333-337.

Bolton, W., \& Oatley, K., (1987). A longitudinal study of social support and depression in unemployed men. Psychological Medicine, 17, 453-460.

Bonoti, F., \& Metallidou, P. (2010). Children's judgments and feelings about their own drawings. Psychology, 1, 329-336. doi:10.4236/psych.2010.15042

Brenner, M. H. (1979). Mortality and the national economy. Lancet, 2, 568-573. doi:10.1016/S0140-6736(79)91626-X

Brenner, S. O., \& Starrin, B. (1988). Unemployment and health in Sweden: Public issues and private troubles. Journal of Social Issues, 44, 125-140. doi:10.1111/j.1540-4560.1988.tb02095.x

Burchell, B. J., Ladipo, D., \& Wilkinson, F. (2002). Job insecurity and 
work intensification. London: Routledge.

Cantor-Graae, E., \& Selten, J. P. (2005). Schizophrenia and migration: A meta-analysis and review. American Journal of Psychiatry, 162, 12- 24.

Cohn, R. M. (1978). The effect of employment status change on selfattitudes. Social Psychology, 41, 81-93. doi:10.2307/3033568

Collins English Dictionary (2011). 11th ed., Collins Press.

Dew, M. A., Bromet, E. J., \& Penkower, L. (1992). Mental health effects of job loss in women. Psychological Medicine, 22, 751-764.

doi:10.1017/S0033291700038198

Donovan, R., Jaffe, N., \& Pirie, V. M. (1987). Unemployment among low-income women: An explatory study. Social Work, 32, 301-305.

Dooley, D., \& Catalano, R. (1983). Health effects of economic instability: A test of economic stress hypothesis. Journal of Health and Social Behaviour, 4, 46-60.

Dooley, D., Catalano, R., \& Wilson, G. (1994). Depression and unemployment: Panel findings from the epidemiologic catchment area study. American Journal of Community Psychology, 22, 745-765. doi:10.1007/BF02521557

Fergusson, D. M., Horwood, L. J., \& Lynskey M. T. (1997). The effects of unemployment on psychiatric illness during young adulthood. Psychological Medicine, 27, 371-381. doi:10.1017/S0033291796004412

Ferrie, J. E., Martikainen, P., Shipley, M. J., Marmot, M. G., Stansfeld, S. A., \& Smith, G. D. (2001). Employment status and health after privatisation in white collar civil servants: Prospective cohort study. British Medical Journal, 322, 647-651.

Frese, M., \& Mohr, G. (1987). Prolonged unemployment and depression in older workers: A longitudinal study of intervening variables. Social Sciences and Medicine, 25, 173-178. doi:10.1016/0277-9536(87)90385-6

Fryer, D. M. (1986). Employment deprivation and personal agency during unemployment: A critical discussion of Jahoda's explanation of the psychological effects of unemployment. Social Behaviour, 1, 3-24.

Graetz, B. (1993). Health consequences of employment and unemployment: longitudinal evidence for young men and women. Social Sciences and Medicine, 36, 715-724. doi:10.1016/0277-9536(93)90032-Y

Jahoda, M. (1982). Employment and unemployment: A social-psychological analysis. Cambridge: Cambridge University Press.

Kasl, S. V., \& Cobb, S. (1980). The experience of losing a job: Some effects on cardiovascular functioning. Psychosomatic Medicine, 34, 88-109.

Lamberg, T., Virtanen, P., Vahtera, J., Luukkaala, T., \& Koskenvu, K. (2010). Unemployment, depressiveness and disability retirement: A follow-up study of the Finnish HeSSup population sample. Social Psychiatry Epidemiology, 45, 259-264. doi:10.1007/s00127-009-0063-z

Linn, M. W., Sandifer, R., \& Stein, S. (1985). Effects of unemployment on mental and physical health. American Journal of Public Health, 75, 502- 506. doi:10.2105/AJPH.75.5.502

Marmot, M. G., Adelstein, A. M., Robinson, N., \& Rose, G. (1978). The changing social class distribution of heart disease. British Medical Journal, 2, 1109-1112. doi:10.1136/bmj.2.6145.1109

Marwaha, S., Johnson, S., Bebbington, P., Stafford, M., Angermeyer, M. C., Brugha, T., Azorin, J.-M., Kilian, R., Hansen, K., \& Toumi, M. (2007). Rates and correlates of employment in people with schizophrenia in the UK, France and Germany. British Journal of Psychiatry, 191, 30-37. doi:10.1192/bjp.bp.105.020982

Mckee-Ryan, F. M., Song, Z., Wanberg, C. R., \& Kinicki, A. J. (2005). Psychological and physical well-being during unemployment: A meta-analysis study. Journal of Applied Psychology, 90, 53-76. doi:10.1037/0021-9010.90.1.53

Murphy, G. C., \& Athanasou, J. A. (1999). The effect of unemployment on mental health. Journal of Occupational and Organisational Psychology, 72: 83-99. doi:10.1348/096317999166518

Paul, K. I., \& Moser, K. (2009). Unemployment impairs mental health: Meta-analysis. Journal of Vocational Behaviour, 74, 264-282. doi:10.1016/j.jvb.2009.01.001

Reininghaus, U. A., Morgan, C., Simpson, J., Dazzan, P., Morgan, K., Doody, G. A., Bhugra, D., Leff, J., Jones, P., Murray, R., Fearon, P., \& Craig, T. K. J. (2008). Unemployment, social isolation, achievement-expectation mismatch and psychosis: findings from the AESOP Study. Social Psychiatry and Psychiatric Epidemiology, 43, 743-751. doi:10.1007/s00127-008-0359-4

Secker, J., Grove, B., \& Seebohm, P. (2001). Challenging barriers to employment, training and education for mental health service users: the service user's perspective. Journal of Mental Health, 10, 395-404. doi:10.1080/09638230120041155

Semple, D., \& Smyth, R. (2009) Oxford handbook of psychiatry. Oxford: Oxford University Press. doi:10.1093/med/9780199239467.001.0001

Tandon, R., Keshavan, B. S., \& Nasrallah, H. A. (2008). Schizophrenia. "Just the Facts" What we know in 2008. 2. Epidemiology and etiology. Schizophrenia Research, 102, 1-18. doi:10.1016/j.schres.2008.04.011

Warr, P. (1987). Work, unemployment and mental health. Oxford: Clarendon Press.

Weich, S., \& Lewis, G. (1998). Poverty, unemployment, and common mental disorders: population based cohort study. BMJ, 317, 115-119. 